\title{
Cost-effectiveness of adjuvant chemotherapy with uracil-tegafur for curatively resected stage III rectal cancer
}

\author{
A Hisashige ${ }^{*, 1}$, S Yoshida ${ }^{2}$ and S Kodaira ${ }^{3}$ \\ 'The Institute of Healthcare Technology Assessment, Tokushima 770-0044, Japan; ${ }^{2}$ The Aomori Prefectural Central Hospital, Aomori 030-8553, Japan; \\ ${ }^{3}$ Department of Surgery, the Nerima General Hospital, Tokyo 176-8530, Japan
}

Recently, the National Surgical Adjuvant Study of Colorectal Cancer in Japan, a randomised controlled trial of oral uracil-tegafur (UFT) adjuvant therapy for stage III rectal cancer, showed remarkable survival gains, compared with surgery alone. To evaluate value for money of adjuvant UFT therapy, cost-effective analysis was carried out. Cost-effectiveness analysis of adjuvant UFT therapy was carried out from a payer's perspective, compared with surgery alone. Overall survival and relapse-free survival were estimated by Kaplan-Meier method, up to 5.6 years from randomisation. Costs were estimated from trial data during observation. Qualityadjusted life-years (QALYs) were calculated using utility score from literature. Beyond observation period, they were simulated by the Boag model combined with the competing risk model. For 5.6-year observation, I0-year follow-up and over lifetime, adjuvant UFT therapy gained $0.50,0.96$ and 2.28 QALYs, and reduced costs by $\$ 2457, \$ 177$ I and $\$ 1843$ per person compared with surgery alone, respectively (3\% discount rate for both effect and costs). Cost-effectiveness acceptability and net monetary benefit analyses showed the robustness of these results. Economic evaluation of adjuvant UFT therapy showed that this therapy is cost saving and can be considered as a cost-effective treatment universally accepted for wide use in Japan.

British Journal of Cancer (2008) 99, 1232-1238. doi:I0.1038/sj.bjc.6604666 www.bjcancer.com

Published online 16 September 2008

(c) 2008 Cancer Research UK

Keywords: uracil-tegafur; adjuvant therapy; rectal cancer; economic evaluation

Colorectal cancer is a major health problem worldwide (Beretta et al, 2004; Bernold and Sinicrope, 2006; Monga and O'Connell, 2006). It is the second most frequent cause of cancer death in the United States and most European countries. In Japan, although its number of deaths ranks third, the disease incidence has recently been increasing (Committee of Cancer Statistics, 2005; Ministry of Health, Labor and Welfare, 2006). The prognosis of patients with colorectal cancer has improved steadily over the past several decades, owing to the development of effective therapies (Ragnhammar et al, 2001; Beretta et al, 2004; Bernold and Sinicrope, 2006; Monga and O'Connell, 2006). In practice, surgery remains the primary treatment modality for localised colorectal cancer. Adjuvant therapy is given in an attempt to eradicate micrometastases and to thereby increase the cure rate after surgical resection.

The natural history of rectal cancer differs from that of colon cancer for epidemiological, anatomical and pathophysiological reasons (Beretta et al, 2004; Bernold and Sinicrope, 2006; Monga and O'Connell, 2006). In the adjuvant therapy for stage III rectal cancer, a combined modality therapy consisting of i.v. 5-fluorouracil (5-FU) and radiotherapy is the standard care (Beretta et al, 2004; Bernold and Sinicrope, 2006; Monga and O'Connell, 2006). However, the use of chemotherapy has been based on the evidence of postoperative adjuvant chemotherapy in colon cancer, not rectal cancer (Takiuchi, 2006). In rectal

*Correspondence: Dr A Hisashige; E-mail: akih@k3.dion.ne.jp Received 13 May 2008; revised 21 August 2008; accepted 22 August 2008; published online 16 September 2008 cancer, there is only one adjuvant therapy (i.e., the MOF in the NSABP R-01 study), which showed improvement of overall survival (OS) and disease-free survival (DFS), compared with surgery alone as the control (Fisher et al, 1988). The optimal timing of adjuvant therapy and the combination of agents continue to evolve. As with in colon cancer (André et al, 2004; Twelves et al, 2005; Bernold and Sinicrope, 2006; Lembersky et al, 2006; Monga and O'Connell, 2006), trials of the combinations of several active drugs, such as oral fluoropyrimidines (i.e., uraciltegafur (UFT) and capecitabine), oxaliplatin and irinotecan, are under way (Bernold and Sinicrope, 2006; Monga and O’Connell, 2006).

As to radiotherapy, a meta-analysis confirmed that postoperative adjuvant radiotherapy significantly reduced local recurrence, but not overall and cancer-specific mortality (Colorectal Cancer Collaborative Group, 2001). In contrast, meta-analyses have shown that preoperative radiotherapy reduces local recurrence, and overall and/or cancer-specific mortality (Cammà et al, 2000). However, randomised controlled trials (RCTs) included in these meta-analyses all started before the broad introduction of total mesorectal excision (TME). The RCT of TME with or without preoperative radiotherapy showed that there was no difference in OS and DFS, except for local recurrence (Kapiteijn et al, 2001). Preoperative chemoradiotherapy, as compared with postoperative chemoradiotherapy, decreased local recurrence, but improved neither OS nor DFS (Sauer et al, 2004). Moreover, preoperative short-term radiotherapy was suggested to cause delayed adverse reactions (Peeters et al, 2005). Therefore, preoperative adjuvant radiotherapy or chemoradiotherapy for rectal cancer should also be carefully evaluated. 
In Japan, in contrast to Europe and the United States above, postoperative adjuvant chemotherapy using oral fluoropyrimidines such as UFT, without radiation, has been the primary treatment, mainly because of excellent outcomes of TME with lateral pelvic lymphadenectomy (Takiuchi, 2006). The local recurrence rate in this extended TME was estimated to be lower than simple TME (Akasu and Moriya, 1997; Mori et al, 1998). Although individual RCTs comparing oral fluoropyrimidines with surgery alone showed improvement in both DFS and local recurrence in rectal cancer, but not in OS (Kodaira et al, 1998; Kato et al, 2002), meta-analyses of RCTs related to fluoropyrimidines in the 1980s showed significant benefits in both DFS and OS (Sakamoto et al, 1999; Meta-Analysis Group, 2004). In contrast, there has been no evaluation on DFS and OS in other therapies including 5-FU/leucovorin (LV) and radiation, in Japan. On the basis of the evidence, UFT is indicated as the first-line treatment of adjuvant chemotherapy after surgery for stage III rectal cancer in Japan (Japan Society for Cancer of the Colon and Rectum, 2005).

Recently, the National Surgical Adjuvant Study of Colorectal Cancer (NSAS-CC) in Japan (Akasu et al, 2006), an RCT of UFT adjuvant therapy for stage III rectal cancer, showed remarkable OS and RFS gains, compared with surgery alone. These results may be attributed to a higher dosage of UFT, rigorous surgical procedures and high quality of the clinical trial. The dosage of UFT per day of $600 \mathrm{mg}$ in this study was greater than the $300-400 \mathrm{mg}$ used in previous UFT studies (Kodaira et al, 1998; Sakamoto et al, 1999; Kato et al, 2002; Meta-Analysis Group, 2004). In this study, TME with lateral pelvic lymphadenectomy was chosen as the control treatment.

Under these circumstances of treatment evolution in rectal cancer, patients and physicians have to consider risks and benefits in choosing the best treatment between the different options now available. On the other hand, health-care payers increasingly require evidence of economics in addition to the clinical value, under the severe pressure to health-care expenditure. However, there is far less economic evaluation specifically of adjuvant therapy for rectal cancer than for colon cancer (van den Hout et al, 2002). Only one study, related to cost-effectiveness of adjuvant therapy for rectal cancer, has been reported (Norum et al, 1997). Our objective was to confirm the cost-effectiveness of adjuvant UFT therapy in Japan, extrapolating these results to a time horizon sufficiently distant to capture all costs and outcomes of relevance. This study would provide basic information on the costeffectiveness of adjuvant therapy for rectal cancer not only in Japan, but also in other countries indirectly.

\section{MATERIALS AND METHODS}

\section{Analytical overview}

Economic analysis was conducted retrospectively based on the Japanese NSAS-CC (Akasu et al, 2006), a multicentre RCT. Patients with completely resected stage III rectal cancer, who underwent standardised TME with selective lateral pelvic lymphadenectomy, were randomly assigned to either oral UFT ( $400 \mathrm{mg} \mathrm{m}^{-2}$ per day) for 1 year $(n=139)$ or surgery alone $(n=135)$.

As a type of economic analysis (Drummond et al, 2005), a costeffective analysis was performed. Incremental costs and effectiveness of adjuvant UFT therapy compared with surgery alone were evaluated. According to the effectiveness measure used (i.e., lifeyears gained and quality-adjusted life-years (QALYs) gained), incremental cost-effectiveness ratios (ICERs) were calculated based on cost per life-year gained and cost per QALY gained, respectively. In a narrow meaning, the former is termed costeffectiveness analysis, whereas the latter is termed cost-utility analysis.

The payer of National Health Insurance in Japan was adopted as a perspective of economic analysis (Drummond et al, 2005).
Therefore, for costs, direct medical-care costs (e.g., costs of tests, drugs, health-care personnel and so on) were examined, whereas indirect costs (e.g., time costs or production loss among patients and their families) were not considered. As a time horizon for evaluation, three levels of time periods (i.e., observational period (5.6 years), 10-year follow-up and over lifetime) were considered. As the base case analysis, observational period was used, as this period incorporated few assumptions for the evaluation.

\section{Effectiveness}

The results of the NSAS-CC were used as evidence of effectiveness in the economic analysis. The clinical results have been presented in detail elsewhere (Akasu et al, 2006). As is shown in Table 1, between the UFT therapy group and the surgery alone group, no statistical differences were observed in age, sex, tumour location or pathological tumour stage. The incidence of adverse events more than grade 3 in the UFT therapy group was higher than that in the surgery alone group. The OS and RFS rates in the UFT therapy group were higher than those in the surgery alone group (Akasu et al, 2006).

Using patients' data, OS and RFS were estimated by the KaplanMeier method, up to 5.6 years from randomisation. Beyond the observation period of 5.6 years, OS was simulated using the Boag model (Boag, 1949) combined with the competing risk model (Gross and Clark, 1975; Maetani et al, 2004) (Figure 1). Commonly used methods for extrapolating the survival data beyond the observation include Weibull, Gompertz, exponential, log-normal and generalised gamma distributions (Lee and Go, 1997). However,

Table I Characteristics of subjects and clinical outcomes

\begin{tabular}{|c|c|c|}
\hline & $\begin{array}{l}\text { UFT } \\
\text { therapy }\end{array}$ & $\begin{array}{l}\text { Surgery } \\
\text { alone }\end{array}$ \\
\hline Number of patients & 139 & 135 \\
\hline Age (median) & 59 & 58 \\
\hline Sex (male) & 84 & 83 \\
\hline \multicolumn{3}{|l|}{ Location of the tumour } \\
\hline Below the promontrium & 43 & 39 \\
\hline Below the lower edge of the second sacral bone & 39 & 44 \\
\hline $\begin{array}{l}\text { Below the rectouterine fossa or rectovesical } \\
\text { fossa }\end{array}$ & 58 & 53 \\
\hline \multicolumn{3}{|l|}{ Pathological tumour stage $\mathrm{e}^{\mathrm{a}}$} \\
\hline $\mathrm{TI}$ & 8 & 11 \\
\hline $\mathrm{T} 2$ & 21 & 16 \\
\hline T3 & 94 & 91 \\
\hline $\mathrm{T} 4$ & 17 & 18 \\
\hline \multicolumn{3}{|l|}{ Pathological nodal stage ${ }^{\mathrm{a}}$} \\
\hline NI & 89 & 90 \\
\hline N2 & 22 & 22 \\
\hline N3 & 29 & 24 \\
\hline Positive lateral pelvic & 11 & 7 \\
\hline & & \\
\hline Adverse event more than grade 3 & 24 & 5 \\
\hline \multirow[t]{2}{*}{ No. of recurrences } & 32 & 53 \\
\hline & $\%$ & $\%$ \\
\hline \multirow{3}{*}{$\begin{array}{l}\text { 3-year survival }(95 \% \mathrm{Cl}) \\
\text { 3-year relapse-free } \\
\text { survival }(95 \% \mathrm{Cl})\end{array}$} & $91(86-97)$ & $81(73-88)$ \\
\hline & & \\
\hline & $78(7 \mid-86)$ & $60(5 \mid-69)$ \\
\hline
\end{tabular}




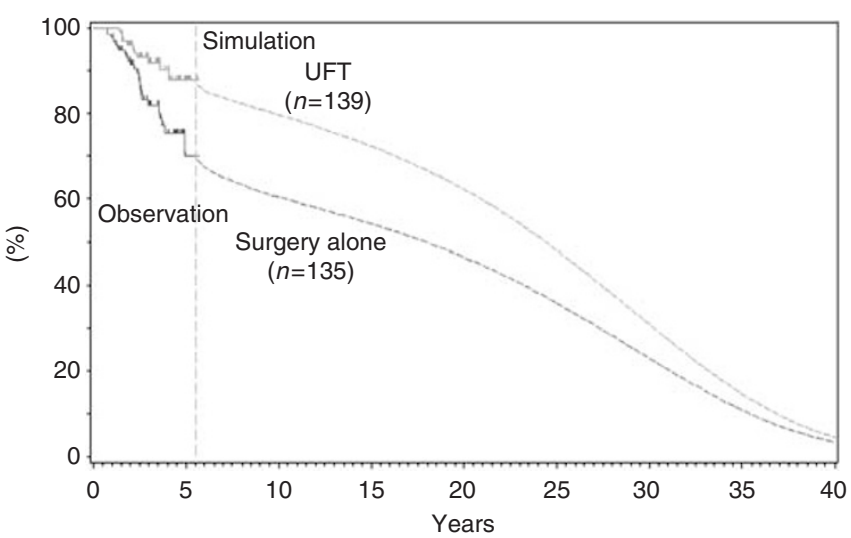

Figure I Observed survival curve and extrapolated survival estimate.

there is no explicit standard for deciding the optimal method. In this analysis, the Boag model combined with the competing risk model was used. This model consisted of two components: the disease-specific survival curve and the disease-independent survival curve. Although the former was simulated by a loglogistic model, the latter was simulated by the survival curve of the general population matched for age and sex of the subjects. Instead of the log-normal model adopted in the original Boag model, the log-logistic model was selected in this analysis, according to Akaike's Information Criteria (Akaike, 1974).

The mean number of life-years and relapse-free life-years for patients in each group was estimated as the area under RFS and OS curves (Willan and Briggs, 2006). In addition, QALYs were estimated from OS and RFS by weighting each survival by utility value for each possible health state. Utility values for the health states were derived from the published study by Ness et al (1999). This study was identified by a systematic literature search using MEDLINE and EMBASE and critically appraised. The median utility (25th, 75th percentile) for stage III after surgery and metastasis was $0.75(0.55,0.85)$ and $0.20(0.00,0.40)$, respectively. These utility values were assigned to the health conditions with and without relapse in this analysis. Although the frequency and grade of adverse events due to chemotherapy was relatively low, utility reduction associated with these events was adjusted by the method adopted by Aballéa et al (2007).

\section{Cost}

Costs incurred for resources used during trial and subsequent follow-up were estimated from trial data and their extrapolation. Resource utilisation during trial and follow-up was derived from individual patient history data. As observations on many patients are censored in a clinical trial, subsequent costs are unknown. To correct for censoring, the cost history method proposed by Lin et al (Lin et al, 1997; Willan and Briggs, 2006) was applied. Costs were estimated from the National Health Insurance perspective using the National Health Insurance reimbursement list and drug price in 2005 (Institute of Social Insurance, 2005; Jiho, 2005). Unit costs for chemotherapy (UFT), consultation and diagnostic tests were low, whereas those of imaging tests for follow-up were relatively high. Admission fees were considerably lower than those in the United States.

Resource utilisation for an adverse event treated on an outpatient basis was estimated for individual patients on standard management. The treatment was relatively simple and at a low cost. The cost of a recurrence was estimated according to the type of recurrence, based on patients' records during observation. The majority of recurrence was at distant sites, and chemotherapy (e.g., FOLFOX4) is recommended as the first-line therapy in the
Japanese guidelines (Japan Society for Cancer of the Colon and Rectum, 2005). The costs associated with end-of-life care for rectal cancer were estimated in the same way as for recurrence. Unrelated health-care costs in the later years of life were not included in this analysis (Drummond et al, 2005). All costs were converted from Japanese yen to US dollars based on OECD purchasing power parity in 2005 ( $\$ 1=¥ 128$ ) (OECD, 2007).

\section{Discount}

Discounting for the time value of money was applied to both costs and effectiveness. In the base case analysis, both costs and effectiveness accruing beyond 1 year were discounted to present values at a rate of $3 \%$, following the recommendations of the US Panel on Cost-Effectiveness in Health and Medicine (Gold et al, 1996). However, currently, much debate still surrounds two major points: the underlying discounting model and the differential discount rate for health and cost (Gold et al, 1996; National Institute of Clinical Excellence, 2004; Bos et al, 2005; Brouwer et al, 2005). Therefore, impact of discounting on the results was examined extensively by sensitivity analysis.

\section{Sensitivity analysis}

The uncertainty of the results was explored by stochastic and qualitative sensitivity analyses of important factors (Glick et al, 2001; Briggs, 2004; Drummond et al, 2005). The impact of uncertainty on the estimated ICER due to the stochastic nature of sampled data was analysed by applying a non-parametric bootstrap resampling technique (i.e., 5000 times) to both costs and effectiveness. Also, cost-effectiveness acceptability and net monetary benefit (NMB) analyses (Glick et al, 2001; Briggs, 2004) were performed. A number of qualitative one-way and two-way sensitivity analyses were conducted to explore the impact of alternative parametric assumptions on the results. These included alternative assumptions concerning time horizon, key cost parameters, recurrence rate, utility value and discount rate.

\section{Budget impact analysis}

To estimate the potential impact of introduction of adjuvant UFT therapy, instead of surgery alone, on the National Health Insurance budget in Japan, a budget impact analysis (Trueman et al, 2001) was performed. The total annual cost to the National Health Insurance was estimated using the treatment costs for adjuvant UFT therapy and surgery alone in cost-effective analysis. The time horizon considered in this analysis was 5.6 years for observation period of the NSAS-CC. The costs were discounted at $3 \%$ of annual rate. The annual number of the resected stage III rectal cancer in Japan was estimated multiplying the annual incidence rate of rectal cancer (Ministry of Health, Labor and Welfare, 2006) by the proportion of the stage III patients who received initial treatment, at the National Cancer Centre in Japan (Committee of Cancer Statistics, 2005).

\section{RESULTS}

\section{Effectiveness}

The mean LYs and QALYs (3\% discount rate) in each group are shown in Table 2A. For 5.6-year observation, 10-year follow-up and over lifetime, the mean QALYs for adjuvant UFT therapy were $3.30,5.43$ and 10.68 , respectively. Those for surgery alone were $2.81,4.47$ and 8.38, respectively. Adjuvant therapy gained $0.50,0.96$ and 2.28 QALYs $(P<0.05)$. The difference in QALYs was larger than that in LYs for the 5.6-year observation, but this pattern was reversed for 10-year follow-up and over lifetime periods. 
Table 2 Incremental effectiveness and costs of adjuvant UFT therapy (discount rate: $3 \%$ for both effectiveness and costs)

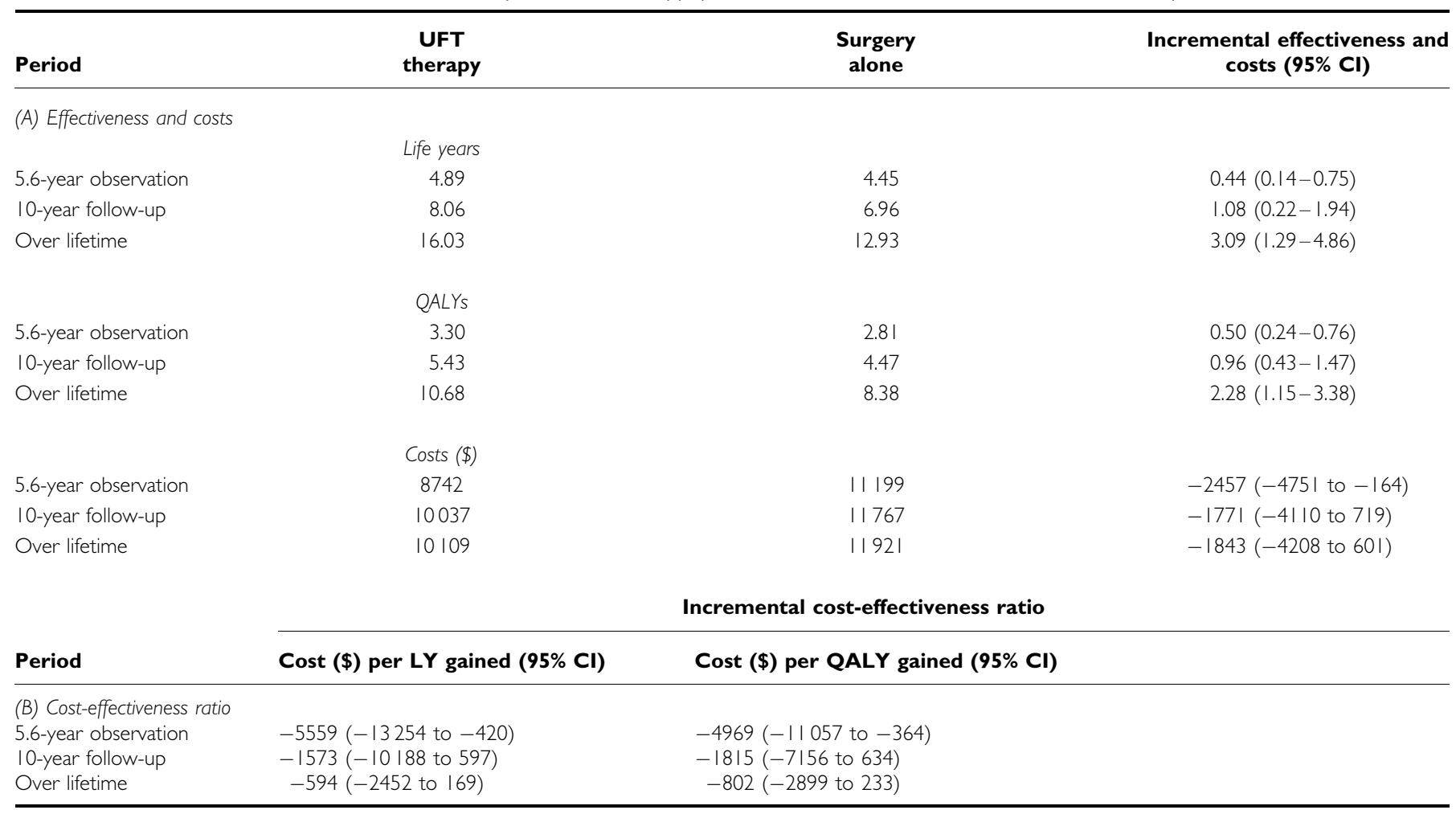

$\mathrm{Cl}=$ confidence interval; $\mathrm{QALYs}=$ quality-adjusted life-years; $\mathrm{UFT}=$ uracil-tegafur.

Table 3 Mean costs per patient during observation period (no discounting)

\begin{tabular}{lcc}
\hline Item & UFT therapy & Surgery alone \\
\hline Consultation & $125(\$)$ & $56(\$)$ \\
Treatment & & \\
$\quad$ Drugs & 3076 & $\mathrm{NA}$ \\
$\quad$ Prescription & 66 & $\mathrm{NA}$ \\
Tests & & \\
Diagnostic tests & 346 & 185 \\
Imaging tests & 1068 & 1098 \\
Side effects & 2 & 1 \\
Recurrence & 3212 & 5061 \\
End of life & 2131 & 6226 \\
Total costs & 10026 & 12628 \\
\hline
\end{tabular}

NA $=$ not applicable; UFT $=$ uracil-tegafur.

\section{Cost}

The mean costs (no discounting) per person in each group for the 5.6-year observation are shown in Table 3. The mean total cost per patient was $\$ 10026$ in the UFT therapy group and $\$ 12628$ in the surgery alone group. The costs of recurrence and end-of-life were the major components in both groups. Although UFT therapy added over $\$ 3000$ per patient to the ingredient cost of surgery alone, this was offset by the reduction of costs in recurrence and end-of-life of rectal cancer. As is shown in Table 2A, for 5.6-year observation, 10-year follow-up and over lifetime, adjuvant UFT therapy reduced costs ( $3 \%$ discount rate) per person by $\$ 2457$, $\$ 1771$ and $\$ 1843$ compared with surgery alone, respectively. The difference in the 5.6-year observation was statistically significant $(P<0.05)$.

\section{Incremental cost-effectiveness ratio}

Uracil-tegafur therapy showed dominance (less costly and more effective). As is shown in Table 2B, ICER for 5.6-year observation, 10 -year follow-up and over lifetime was estimated to be $-\$ 4969$, $-\$ 1815$ and $-\$ 802$ per QALY gained, respectively, using the bootstrap method ( $3 \%$ discount rate for both effect and cost). There is little difference between costs per life-year gained and costs per QALY gained.

\section{Sensitivity analysis}

The results of a probabilistic sensitivity analysis are shown in Figure 2. Figure 2A shows ICER (cost per QALY gained) scatter plots. More than $95 \%$ of the points resided in the southeast quadrant (i.e., more effective and less costly). The cost-effectiveness acceptability cure based on 5000 samples of cost-effectiveness ratio is presented in Figure 2B. Even if additional QALY was valued as 0 , the likelihood of UFT therapy being cost-effective was $98 \%$. The NMB curve is shown in Figure $2 \mathrm{C}$. The $\mathrm{NMB}$ and its confidence interval (CI) curves did not cross the horizontal axis. This indicates that UFT therapy was beneficial, even if a decision maker was not willing to pay anything for the additional QALY.

A number of qualitative sensitivity analyses are shown in Tables $2 \mathrm{~B}$ and 4 . As to time horizon (Table 2B), from 5.6-year observation to over lifetime, cost-effectiveness ratios were all negative, indicating more benefits and less costs (i.e., dominance).

The two-way sensitivity analysis of discount rate for both costs and effect did not show any change in the dominance of UFT therapy. Incremental cost-effectiveness ratio was lowest $(-\$ 5031$ per QALY) at a discount rate of $5 \%$ for both costs and effectiveness and 
A

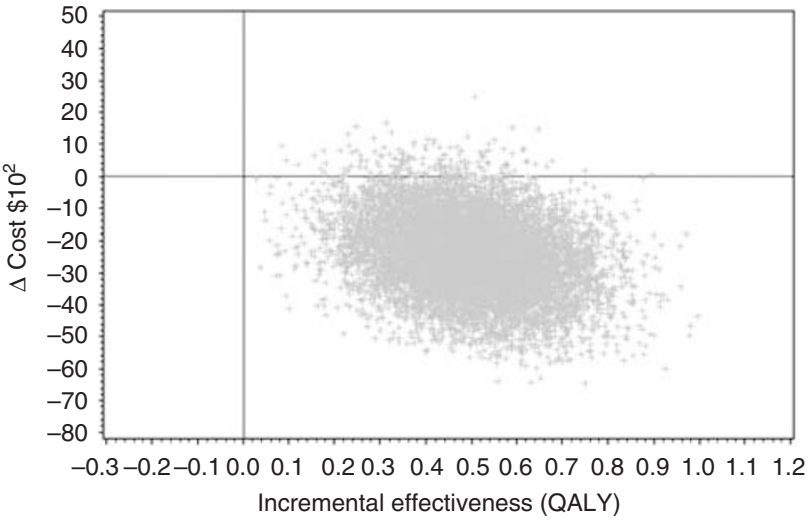

B
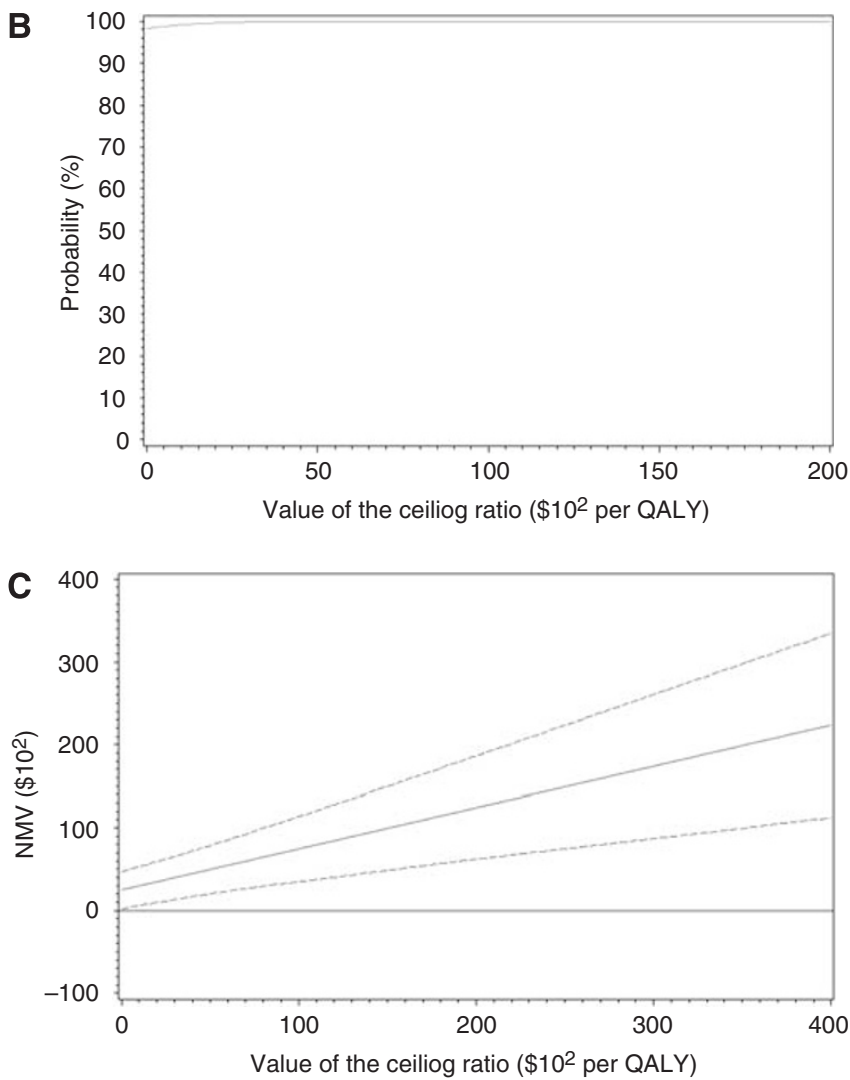

Figure 2 Stochastic sensitivity analyses. (A) Incremental cost-effectiveness scatter plot of UFT therapy. (B) Cost-effectiveness acceptability curve of adjuvant UFT therapy. (C) Net monetary benefit curve of adjuvant UFT therapy with $95 \%$ confidence intervals.

highest ( $-\$ 4933$ per QALY) without discounting. Incremental costeffectiveness ratio increased with increase of discount rate of cost, whereas ICER decreased with increase of discount rate of effect.

The results of one-way sensitivity analyses are shown in Table 4. Variations in recurrence rate, utility value, QALYs and the acquisition cost of UFT did not influence the dominance of UFT therapy. On the other hand, with variations of total cost, ICERs varied from $-\$ 9695$ to $\$ 334$ per QALY gained. This upper limit of ICER was positive, but at a very low level.

\section{Budget impact}

The annual incidence rate of rectal cancer was $3.23 \times 10^{4}$ and the proportion of the stage III patients was $32.5 \%$. Then, the annual
Table 4 One-way sensitivity analysis of important factors

\begin{tabular}{lc}
\hline Factor & $\begin{array}{c}\text { Cost-effectiveness ratio } \\
\text { (\$ per QALY gained) }\end{array}$ \\
\hline Base case analysis & -4969 \\
Recurrence rate $(95 \% \mathrm{Cl})$ & \\
Utility $(25$ th, 75 th percentile) & \\
$\quad$ Non-recurrence & -7063 to -4328 \\
Recurrence & -5593 to -4471 \\
QALY $(95 \% \mathrm{Cl})$ & -10434 to -3244 \\
UFT cost $(95 \% \mathrm{Cl})$ & -7506 to -2432 \\
Total cost $(95 \% \mathrm{Cl})$ & -9695 to 334 \\
\hline
\end{tabular}

$\mathrm{Cl}=$ confidence interval; $\mathrm{QALY}=$ quality-adjusted life-year; UFT = uracil-tegafur Discount rate: $3 \%$ for both cost and effectiveness; period: observation.

number $(95 \% \mathrm{CI})$ of the resected stage III rectal cancer was estimated to be $1.05 \times 10^{4}(0.91-1.20)$. The cost reduction per patient was $\$ 2603$. Therefore, a budget impact converting from surgery alone to adjuvant UFT therapy would reduce current medical expenditure by $\$ 27.3$ million (95\% CI, $\$ 23.7$ million, $\$ 31.2$ million) in the first 5.6 years after its adoption.

\section{DISCUSSION}

From the perspective of the National Health Insurance in Japan, this cost-effectiveness analysis of UFT adjuvant therapy for stage III rectal cancer would save health-care costs and improve health outcomes, compared with surgery alone (Table 2). Uracil-tegafur therapy has proved dominant (less costly and more effective). The cost - utility ratio of UFT can be ranked near the top of league table of cost-utility in oncology (Earle et al, 2000). The cost savings on the National Health Insurance budget during the observational period would be approximately $\$ 27.3$ million.

There has been little evidence on economic evaluation of adjuvant therapy for rectal cancer (van den Hout et al, 2002). Only one cost-effective analysis of adjuvant therapy for Dukes' B and C colorectal cancer (Norum et al, 1997), of which about two-third consisted of colon cancer, has shown that cost per QALY gained of 5-FU/levamisole was between $£ 4800$ and $£ 16,800$, compared with surgery alone. This result is highly cost-effective compared with the recent threshold (Jonsson, 2004) for cost-effectiveness. However, cost-effectiveness ratio in our study is much better than that, even though these results are not directly comparable with each other. In the area of rectal cancer, economic evaluations on the standard adjuvant therapy (i.v. 5-FU/radiation) comparing control (i.e., surgery alone), as well as head-to-head evaluation comparing newly emerging with the standard therapy, are urgently needed for health-care decision making. Our study provides basic information in comparing cost-effectiveness of adjuvant therapies for rectal cancer.

To estimate stochastic uncertainty of ICER due to sampling bias in this study, probabilistic sensitivity analyses (Glick et al, 2001; Briggs, 2004; Drummond et al, 2005) were performed (Table 2, Figure 2). Cost-effectiveness scatter plots showed that CIs of ICER located in the southeast quadrant (more effective and less costly) on the cost-effectiveness plane. Cost-effectiveness acceptability and $\mathrm{NMB}$ curves give more information than simple intervals or plots of ICERs mentioned above. Even if a decision maker was unwilling to invest anything at the maximum to achieve additional QALY, the likelihood of UFT therapy being acceptable as costeffective was $98 \%$ (Figure 2B). At the same condition, the NMB curve showed that UFT therapy was beneficial ( $\$ 2450$ per person) (Figure 2C). These results show that the dominant cost-effectiveness of UFT adjuvant therapy is robust. This dominance was 
shown more sensitive to costs than effectiveness by the scatter plot of ICERs (Figure 2A) and broad one-way sensitivity analysis on both QALY gained and total costs (Table 4).

The time horizon is an important issue to sufficiently capture relevant costs and health outcomes of UFT adjuvant therapy. The observation period of the NSAS-CC, 5.6 years, was limited. Although most costs were incurred mainly in the observational period, life-years gained would continue after it. In this study, a simulation model was used to extrapolate its results. There is a variety of ways for simulation (Lee and Go, 1997), but no uniform methodology is available. In the analysis, we used the Boag model combined with the competing risk model (Maetani et al, 2004). In a sensitivity analysis, ICER of the observational period (the base case analysis) was compared with that in the extrapolated periods (i.e., 10-year follow-up and over lifetime). These ICERs were dominant (more effective and less costly) in spite of relative differences in their values.

The key drivers of the dominant cost-effectiveness results of UFT are mainly the savings achieved by reduction of costs related to recurrence and death, which offset the acquisition cost of UFT. After a 4-year follow-up, any recurrence has not been observed in this study. In one-way sensitivity analysis (Table 4), varying recurrence rates between $95 \%$ CIs did not have any substantial impact on dominant cost-effectiveness. The other cost driver was the acquisition costs of UFT. Variation in the price of UFT and its standard regimen would be unlikely. Varying acquisition costs of UFT did not have any impact of dominance (Table 4).

Cost-effectiveness analysis using QALYs offers the opportunity to consider both quantity and quality of survival. However, no substantial difference in ICERs was observed between cost per LY gained and QALY gained (Table 2). In addition, the sensitivity analysis on range of utility values for recurrence and nonrecurrence revealed no major change in dominant cost-effectiveness (Table 4). In a sizable fraction of cost-effectiveness analysis, utility weighting was indicated not to substantially alter the estimated cost-effectiveness of an intervention (Chapman et al, 2004). It is thus suggested that sensitivity analyses using ad hoc adjustment or weight from the literature may be sufficient. Our results support this conclusion.

The impact of discounting for the time value of money on the results was examined extensively by two-way sensitivity analyses. Although ICERs were more sensitive to cost discounting than effectiveness discounting, there was no substantial change in dominant cost-effectiveness. The main reason is likely to be that

\section{REFERENCES}

Aballéa S, Chancellor JV, Raikou M, Drummond MF, Weinstein MC, Jourdan S, Bridgewater J (2007) Cost-effectiveness analysis of oxaliplatin compared with 5-fluorouracil/leucovorin in adjuvant treatment of stage III colon cancer in the US. Cancer 109: 1082-1089

Akaike H (1974) A new look at the statistical model identification. IEEE Trans Automat Contr 19: 716-723

Akasu T, Moriya Y (1997) Abdominopelvic lymphadenectomy with autonomic nerve preservation for carcinoma of the rectum: Japanese experience. In Surgery for Gastrointestinal cancer: a Multi-Disciplinary Approach, Wanebo HJ (ed), pp 667-680. Lippincott-Raven: Philadelphia

Akasu T, Moriya Y, Ohashi Y, Yoshida S, Shirao K, Kodaira S (2006) Adjuvant chemotherapy with uracil-tegafur for pathological stage III rectal cancer after mesorectal excision with selective lateral pelvic lymphadenectomy: a multicenter randomized controlled trial. Jpn J Clin Oncol 36: $237-244$

André T, Boni C, Mounedji-Boudiaf L, Navarro M, Tabernero J, Hickish T, Topham C, Zaninelli M, Clingan P, Bridgewater J, Tabah-Fisch I, de Gramont A (2004) Oxaliplatin, fluorouracil, and leucovorin as adjuvant treatment for colon cancer. NEJM 350: 2343-2351

Bajetta E, Bartolomeo MD, Buzzoni R, Mariani L, Zilembo N, Ferrario E, Vullo SL, Aitini E, Isa L, Barone C, Jacobelli S, Recaldin E, Pinotti G, Iop A on behalf of the ITMO group (2007) Uracil/ftorafur/leucovorin major costs were incurred during the early phase of follow-up and improved survival was realised simultaneously.

There are several limitations in the analysis that should be commented on, and the results should be treated with caution. First, the analysis was based on a small RCT with relatively short-term follow-up (Akasu et al, 2006). Therefore, extensive sensitivity analyses were performed to examine this uncertainty. However, large-scale RCTs are crucial to resolving this issue. Second, the UFT adjuvant therapy was the only chemotherapy that showed improvement in OS and DFS compared with surgery alone in Japan. As there is no RCT comparing the standard adjuvant therapy (e.g., 5-FU/radiation) with surgery alone or UFT, it is impossible to directly or indirectly compare these therapies. In future, head-to-head evaluations comparing new emerging therapies (e.g., capecitabine and oxaliplatin) will need to be carried out. Third, the perspective of this analysis is that of a payer for health care, rather than a society. From a societal perspective, the range of costs is broader and includes time costs and travel costs associated with treatment and loss of production due to earlier death. As UFT adjuvant therapy increased OS and decreased recurrence, their cost reduction in both indirect costs and direct costs will offset the costs corresponding to a treatment period.

The issue of generalisability of this study to other countries should be carefully examined, as the UFT adjuvant therapy is the standard in Japan. However, as mentioned in the introduction, in contrast to colon cancer, there is no firm evidence for effectiveness of the western standard therapy (e.g., FU/LV) in rectal cancer. Moreover, given the high treatment costs, substantial toxicity and relatively limited efficacy of the fast-changing chemo- and immunotherapeutic combinations for colorectal cancer, examination of cost-effectiveness studies should be conducted on a routine basis along with determination of clinical benefits (Jansman et al, 2007). Uracil-tegafur has been approved and utilised in 31 countries from Europe and Canada to Asia, excluding the United States. Recently, several studies of combination therapies of UFT/LV in metastatic colorectal cancer have shown efficacy (Bennouna et al, 2006; Bajetta et al, 2007). Therefore, the results of this study indicating effectiveness and cost-effectiveness of UFT adjuvant therapy in rectal cancer may be useful as a reference case for the direct or indirect future examination internationally.

\section{ACKNOWLEDGEMENTS}

Presented at the 2007 Gastrointestinal Cancers Symposium, Orlando, FL, Jan 19-21, 2007. combined with irinotecan (TEGAFIRI) or oxaliplatin (TEGAFOX) as first-line treatment for metastatic colorectal cancer patients: results of randomised phase II study. Br J Cancer 96: 439-444

Bennouna J, Perrier H, Paillot B, Priou F, Jacob JH, Hebbar M, Bordenave S, Seitz JF, Cvitkovic F, Dorval E, Malek K, Tonelli D, Douillard JY (2006) A phase II study of oral uracil/ftorafur (UFTs) plus leucovorin combined with oxaliplatin (TEGAFOX) as first-line treatment in patients with metastatic colorectal cancer. Br J Cancer 94: 69-73

Beretta GD, Milesi L, Pessi MA, Mosconi S, Labianca R (2004) Adjuvant treatment of colorectal cancer. Surg Oncol 13: 63-73

Bernold DM, Sinicrope FA (2006) Advances in chemotherapy for colorectal cancer. Clin Gastroenterol Hepatol 4: 808-821

Boag JW (1949) Maximum likelihood estimates of the proportion of patients cured by cancer therapy. J Roy Stat Soc B 11: 15-53

Bos JM, Postma MJ, Annemans L (2005) Discounting health effects in pharmacoeconomics evaluations: current Controversies. Pharmacoeconomics 23: 639-649

Briggs AH (2004) Statistical approaches to handling uncertainty in health economic evaluation. Eur J Gastroenterol Hepatol 16: 551-561

Brouwer WB, Niessen LW, Postma MJ, Rutten FF (2005) Need for differential discounting of costs and health effects in cost-effectiveness analyses. BMJ 331: $446-448$ 
Cammà C, Giunta M, Fiorica F, Pagliaro L, Craxì A, Cottone M (2000) Preoperative radiotherapy for resectable rectal cancer. JAMA 284: $1008-1015$

Chapman RH, Berger M, Weinstein MC, Weeks JC, Goldie S, Neumann PJ (2004) When does quality-adjusted life-years matter in cost-effectiveness analysis? Health Econ 13: 429-436

Colorectal Cancer Collaborative Group (2001) Adjuvant radiotherapy for rectal cancer: a systematic overview of 8507 patients from 22 randomized trials. Lancet 358: $1291-1304$

Committee of Cancer Statistics (2005) Cancer Statistics 2005. Tokyo (in Japanese): Foundation of Promotion of Cancer Research

Drummond MF, Sculpher MJ, Torrance GW, O'Brien BJ, Stoddart GL (2005) Methods for the Economic Evaluation of Health Care Programmes, 3rd ed Oxford Univ Press: NY

Earle CC, Chapman RH, Baker CS, Bell CM, Stone PW, Sandberg EA, Neumann PJ (2000) Systematic overview of cost-utility assessments in oncology. J Clin Oncol 18: $3302-3317$

Fisher B, Wolmark N, Rockette H, Redmond C, Deutsch M, Wickerham DL, Fisher ER, Caplan R, Jones J, Lerner H (1988) Postoperative adjuvant chemotherapy or radiation therapy for rectal cancer. Results from NSABP protocol R-01. J Natl Cancer Inst 80: 21 - 29

Glick HA, Briggs AH, Polsky D (2001) Quantifying stochastic uncertainty and presenting results of cost-effectiveness analyses. Expert Rev Pharmacoeconomics Outcome Res 1: 89-100

Gold MR, Siegel JE, Russell LB, Weinstein MC (1996) Cost-Effectiveness in Health and Medicine. Oxford Univ Press: NY

Gross AJ, Clark VA (1975) Survival distributions: Reliability Applications in the Biomedical Sciences. John Wiley \& Sons: NY

Institute of Social Insurance (2005) Interpretation for Table of Points of Medical Practice. Institute of Social Insurance: Tokyo (in Japanese)

Jansman FGA, Postma MJ, Brouwers JRBJ (2007) Cost considerations in the treatment of colorectal cancer. Pharmacoeconomics 25: 537-562

Japanese Society for Cancer of the Colon and Rectum (2005) Treatment Guidelines for Colorectal Cancer, 2005 version, Kanehara: Tokyo (in Japanese)

Jiho (2005) Encyclopedia of Drugs Listed for Insurance. Jiho Inc.: Tokyo (in Japanese)

Jonsson B (2004) Changing health environment: the challenge to demonstrate cost-effectiveness of new compounds. Pharmacoeconomics 22(Suppl 4): $5-10$

Kapiteijn E, Marijnen CA, Nagtegaal ID, Putter H, Steup WH, Wiggers T, Rutten HJ, Pahlman L, Glimelius B, van Krieken JH, Leer JW, van de Velde CJ, Dutch Colorectal Cancer Group (2001) Preoperative radiotherapy combined with total mesorectal excision for respectable rectal cancer. NEJM 345: 638-646

Kato T, Ohashi Y, Nakazato H, Koike A, Saji S, Suzuki H, Takagi H, Nimura Y, Hasumi A, Baba S, Manabe T, Maruta M, Miura K, Yamaguchi A (2002) Efficacy of oral UFT as adjuvant chemotherapy to curative resection of colorectal cancer: multicenter prospective randomized trial. Langenbecks Arch Surg 386: 575-581

Kodaira S, Kikuchi K, Yasutomi M, Takahashi T, Hojo K, Kato T, Tominaga T, Kunii Y (1998) Postoperative adjuvant chemotherapy with mitomycin $\mathrm{C}$ and UFT for curatively resected rectal cancer. Results form the Cooperative Project No.7 Group of the Japanese Foundation for Multidisciplinary Treatment of Cancer. Int J Clin Oncol 3: $357-364$

Lee ET, Go OT (1997) Survival analysis in public health research. Ann Rev Pub Health 18: $105-134$

Lembersky BC, Wieand HS, Petrelli NJ, O'Connell MJ, Colangelo LH, Smith RE, Seay TE, Giguere JK, Marshall ME, Jacobs AD, Colman LK, Soran A, Yothers G, Wolmark N (2006) Oral uracil and tegafur plus leucovorin compared with intravenous fluorouracil and leucovorin in stage II and
III carcinoma of the colon: results from National Surgical Adjuvant Breast and Bowel Project Protocol C-06. J Clin Oncol 24: 2059-2064

Lin DY, Feuer EJ, Etzioni R, Wax Y (1997) Estimating medical costs from incomplete follow-up data. Biometrics 53: 419-434

Maetani S, Nakajima T, Nishikawa T (2004) Parametric mean survival time analysis in gastric cancer patients. Med Decis Making 24: 131-141

Meta-Analysis Group of the Japanese Society for Cancer of the Colon and Rectum and the Meta-Analysis Group in Cancer (2004) Efficacy of oral adjuvant therapy after resection of colorectal cancer, 5-year results from three randomized trials. J Clin Oncol 22: 484-492

Ministry of Health, Labor and Welfare (2006) Outline of Vital Statistics. MHLW, (in Japanese)

Monga DK, O’Connell MJ (2006) Surgical adjuvant therapy for colorectal cancer: current approaches and future directions. Ann Surg Oncol 13: $1021-1034$

Mori T, Takahashi K, Yasumo M (1998) Radical resection with autonomic nerve preservation and lymph node dissection techniques in lower rectal cancer surgery and its results: the impact of lateral lymph node dissection. Langenbecks Arch Surg 383: 409-415

National Institute of Clinical Excellence (2004) Guide to the Methods of Technology Appraisal. NICE: London

Ness RM, Holmes AM, Klein R, Dittus R (1999) Utility valuations for outcome states of colorectal cancer. Am J Gastroenterol 94: 1650-1657

Norum J, Vonen B, Olsen JA, Revhaug A (1997) Adjuvant chemotherapy (5-fluorouracil and levamisole) in Dukes' B and C colorectal carcinoma, a cost-effectiveness analysis. Ann Oncol 8: 65-70

OECD (2007) GDP PPPs and Delivered Indices for all OECD Countries, OECD Main Economic Indicators. OECD

Peeters KC, van de Velde CJ, Leer JW, Martijn H, Junggeburt JM, Kranenbarg EK, Steup WH, Wiggers T, Rutten HJ, Marijnen CA (2005) Late side effect of short-course preoperative radiotherapy combined with total mesorectal excision for rectal cancer: increased bowel dysfunction in irradiated patients, a Dutch Colorectal Cancer Group Study. J Clin Oncol 23: 6199-6206

Ragnhammar P, Hafström L, Nygren P, Glimelius B, SBU-group. Swedish Council of Technology Assessment in Health Care (2001) A systematic overview of chemotherapy effects in colorectal cancer. Acta Oncologica 40: $282-308$

Sakamoto J, Hamada C, Kodaira S, Nakazato H, Ohashi Y (1999) Adjuvant therapy with oral fluoropyrimidines as main chemotherapeutic agents after curative resection for colorectal cancer: individual patient data meta-analysis of randomized trials. Jpn J Clin Oncol 29: 78-86

Sauer R, Becker H, Hohenberger W, Rödel C, Wittekind C, Fietkau R, Martus P, Tschmelitsch J, Hager E, Hess CF, Karstens JH, Liersch T, Schmidberger H, Raab R, German Rectal Cancer Study Group (2004) Preoperative versus postoperative chemoradiotherapy for rectal cancer. NEJM 351: $1731-1740$

Takiuchi H (2006) Adjuvant therapy in rectal cancer: what is the truth? Jpn J Clin Oncol 36: $191-192$

Trueman P, Drummond M, Hutton J (2001) Developing guidance for budget impact analysis. Pharmacoeconomics 19: 609-621

Twelves C, Wong A, Nowacki MP, Abt M, Burris III H, Carrato A, Cassidy J, Cervantes A, Fagerberg J, Georgoulias V, Husseini F, Jodrell D, Koralewski P, Kröning H, Maroun J, Marschner N, McKendrick J, Pawlicki M, Rosso R, Schüller J, Seitz JF, Stabuc B, Tujakowski J, Van Hazel G, Zaluski J, Scheithauer W (2005) Capecitabine as adjuvant treatment for stage III colon cancer. NEJM 352: 2696-2704

van den Hout WB, van den Brink M, Stiggelbout AM, van de Velde CJ, Kievit J (2002) Cost-effectiveness analysis of colorectal cancer treatments. Eur J Cancer 38: $953-963$

Willan AR, Briggs AH (2006) Statistical Analysis of Cost-Effectiveness Data. John Wiley \& Sons: Chichester 